Abstracts on this page have been chosen and

edited by Dr Trevor Watts

ORAL MEDICINE; BEHAVIOURAL SCIENCE

\section{Association between optimism and self-reported facial pain}

Sipilä K, Ylöstalo PV et al. Acta Odont Scand 2006; 64: 177-182

Optimism appears inversely related to facial pain.

Optimism is the expectation of positive outcomes in the future, and is associated with some health outcomes, including lower pain levels. In this study, 8,463 subjects in a Finnish birth cohort from 1966 (31-year-olds) were asked to attend for examination, and 5,696 responders (67\%) were given questionnaires on facial pain, optimism and depression.

In these subjects the 4 levels of optimism were inversely associated with depressiveness, which agrees with other studies. Among non-depressive subjects, the 2 highest levels of optimism were significantly associated with a lower likelihood of experiencing facial pain. In depressive subjects, there was no association of optimism with facial pain. The authors suggest that optimism and depressiveness are independent determinants of facial pain, but note that their study was cross-sectional, and therefore causality cannot be inferred.

doi:10.1038/sj.bdj.4814170

\section{CARIOLOGY}

\section{The influence of enamel defects on the} development of early childhood caries in a population with low socioeconomic status: a longitudinal study

Oliviera AFB, Chaves AMB et al. Caries Res 2006; 40: 296-302

Enamel defects are strongly associated with early childhood caries in poor communities.

Caries levels are higher in deprived children. Factors including economic status, malnutrition, and infection rates are related to their caries experience. A group of 275 Brazilian children from an area of extreme poverty was recruited at birth, and 246 were examined at $1 \mathrm{yr}$ of age, of whom 228 were followed up to age 3. Subjects were examined and their parents were interviewed.

Enamel defects were present in 180 children, of whom 56 had caries at 3 yrs, and caries was present in only one of the 48 children without such defects $(P=0.0001 ; \mathrm{OR}=14.9,95 \% \mathrm{CI}=2.1-105)$. Caries was found in 219 of 4469 teeth examined, most often related to hypoplastic defects. Caries was present in only 30 of 3348 teeth without enamel defects. Night breast-feeding and poor oral hygiene at 18 and 24 months were also predictors of caries, but by 30 months, only enamel defects predicted caries at 36 months. The authors suggest that governments in such areas should seek to improve nutrition and living conditions for children.
ORAL MEDICINE; NEPHROLOGY

\section{Oral health in renal transplant recipients administered cyclosporin A or tacrolimus}

Spolidorio LC, Spolidorio DMP et al. Oral Diseases 2006; 12: 309-314

Subjects on cyclosporin had more oral complications.

Cyclosporin and tacrolimus are immunosuppressive drugs used in transplant recipients. Gingival overgrowth is associated with the use of cyclosporin, but little or none is seen in subjects receiving tacrolimus. Calcium channel blockers (CCBs), used to control hypertension in some of these patients, also may cause gingival enlargement. In a Brazilian hospital, 88 renal transplant subjects receiving cyclosporin (64 also receiving a $\mathrm{CCB}$ ) and 67 receiving tacrolimus ( 6 receiving a CCB) were examined for oral conditions.

All subjects were considered to have satisfactory oral hygiene. In subjects receiving cyclosporin and a CCB, 54 showed gingival overgrowth, but only 14 on cyclosporin alone showed this. All 6 on tacrolimus and a CCB had overgrowth, but none on tacrolimus alone. Candidal infection was commoner in subjects on cyclosporin. In subjects on cyclosporin alone, 10 had herpes simplex infection and 3 had squamous cell carcinoma of the lip. The authors discuss the relevance of findings to the medication.

doi:10.1038/sj.bdj.4814171

ORAL PATHOLOGY; ORAL SURGERY

\section{Recurrence related to treatment modalities of unicystic ameloblastoma:} \section{a systematic review}

Lau SL, Samman N. Int J Oral Maxillofac Surg 2006; 35: 681-690

\section{A resective approach gave the best result.}

This review attempted to identify which treatment for unicystic ameloblastoma gave the lowest rate of recurrence. The lesion may be clinically misdiagnosed as a cyst, but its rarity makes good evidence difficult to obtain. Altogether 61 potentially relevant articles were identified.

Following critical appraisal, just 6 articles satisfied criteria for the final review. All were retrospective, and related to 132 patients (half male; mean age 26 yrs, range 13-79; 96\% in the mandible) with the condition. Patients with less than 5 yrs' follow-up were excluded, leaving 100. Recurrence rates were 3.6\% for resection (28 patients), 30.5\% for enucleation alone (36), 16\% for enucleation followed by Carnoy's solution application (25), and 18\% by marsupialisation (11) followed by enucleation (where the lesion reduced in size) or resection. The authors consider that marsupialisation could not be evaluated because of the follow-up procedures, but stress that resection should not be mandatory because of other clinical considerations.

doi:10.1038/sj.bdj.4814173 